\title{
Geociências Geosciences
}

\section{O meteorito condrítico ordinário L5(S5) de queda em Guaçuí, ES-Brasil}

\section{The L5(S5) ordinary chondritic meteorite from Guaçuí, ES-Brazil}

\begin{abstract}
Alexandre de Oliveira Chaves
Instituto de Geociências da Universidade Federal de Minas Gerais (IGC-UFMG) alochaves@yahoo.com.br
\end{abstract}

Caio Vinícius Gabrig Turbay Rangel

Centro de Ciências Agrárias da Universidade Federal do Espírito Santo (CCA-UFES) cturbay@gmail.com

\section{Geraldo Norberto Chaves Sgarbi} Instituto de Geociências da Universidade Federal de Minas Gerais (IGC-UFMG) gncsgarbi@gmail.com

\section{Antonio Wilson Romano}

Instituto de Geociências da Universidade

Federal de Minas Gerais (IGC-UFMG)

romanoaw@gmail.com

\section{Luís Rodrigues Armôa Garcia}

Laboratório de Microanálises do

Consórcio IGC-FÍSICA-QUÍMICA/UFMG

e CDTN/CNEN

Irgarcia@fisica.ufmg.br

Figura 1

Amostra de meteorito encontrada no município de Varre-Sai (RJ).

Figura 2 Amostra do meteorito investigada neste artigo, encontrada no município de Guaçuí-ES.

\section{Resumo}

Após 19 anos desde o registro da última queda de meteorito no Brasil, uma nova queda foi registrada em Guaçuí-ES em junho de 2010. As características químicas, mineralógicas e texturais apresentadas pelo recém descoberto meteorito de Guaçuí permitem classificá-lo como um condrito ordinário do tipo L5(S5).

Palavras-chave: Meteorito, condrito, Guaçuí.

\section{Abstract}

After 19 years, a new meteorite fall has been recorded in Brazil. Chemical, mineralogical and textural record of the meteorite fallen in Guaçui-ES in June 2010 allows to classify it as an L5(S5) ordinary chondrite.

Keywords: Meteorite, chondrite, Guaçuí.

\section{Introdução}

Aproximadamente às $17 \mathrm{~h} 40 \mathrm{~min}$ da tarde, do dia 19 de junho de 2010, diversas pessoas testemunharam um rastro de fumaça que cortava o céu na porção sul do Estado do Espírito Santo, que posteriormente se desdobrou na explosão

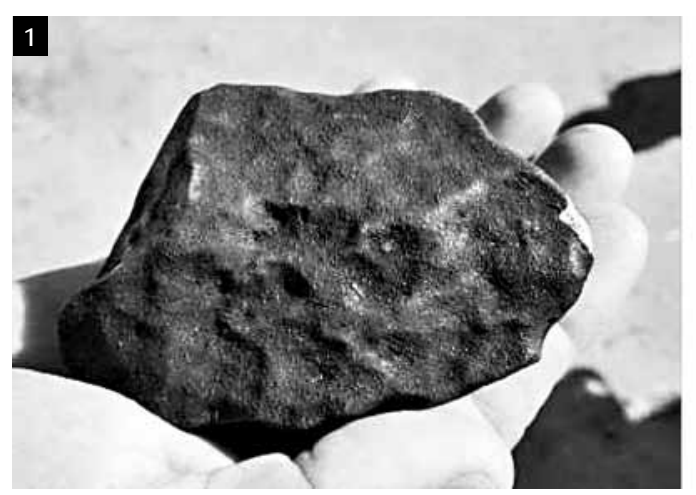

de uma bola de fogo laranja. No mesmo dia foi descoberto um pedaço de um meteorito, com aproximadamente 600 gramas e 12 centímetros na sua maior dimensão (Figura 1), por um agricultor do município de Varre-Sai, Estado do Rio

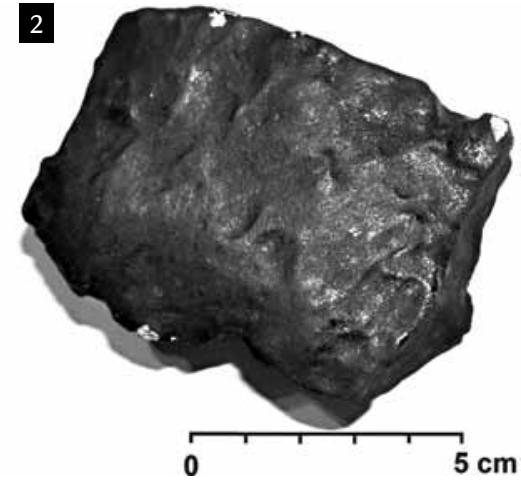


de Janeiro, que faz limite com o Estado do Espírito Santo por meio do Rio Itabapoana. Segundo a prefeitura da cidade, Germano Oliveira, 62 anos, escutou um barulho dentro de sua propriedade rural e, em seguida, descobriu o que achava ser apenas uma pedra.

Uma semana depois, a poucos quilômetros da primeira descoberta, o agricultor Antônio Jevu Sobrinho encontrou outro pedaço, agora do outro lado da margem do Rio Itabapoana, no município de Guaçuí - Espírito Santo (coordenadas UTM 0215324, 7691847; fuso 24K; Datum: WGS84). Este pedaço, juntamente com o primeiro caído em terras fluminenses, certamente derivou da desintegração

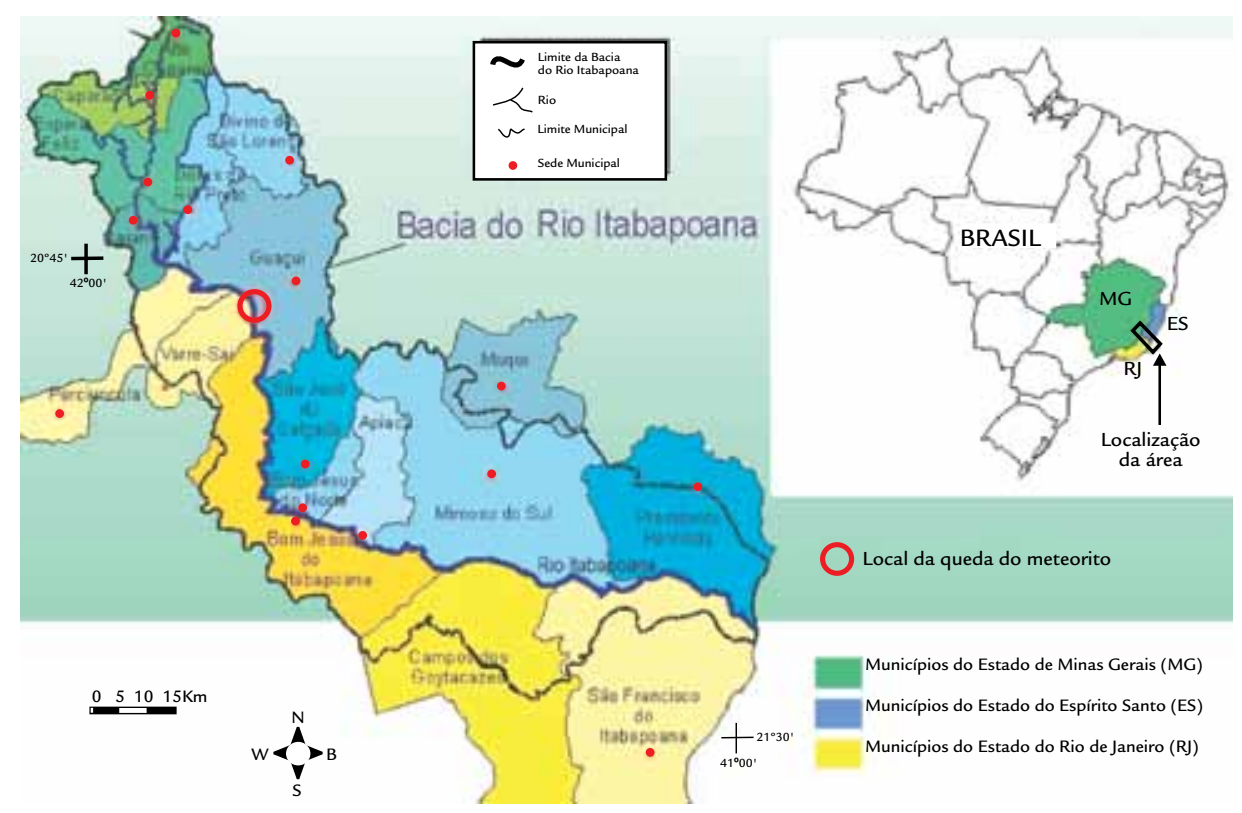
de fogo em 19/06/2010. Contatados por funcionários da prefeitura de Guaçuí-ES, os autores foram ao local e conseguiram a guarda provisória do meteorito (Figura 2) para análises. A localização do ponto de queda de ambos os fragmentos encontrase na Figura 3.

Até a data deste manuscrito, foram noticiadas pela imprensa as descobertas de três fragmentos, o terceiro também no município de Varre-Sai (RJ). Sabe-se que o primeiro fragmento fluminense encontrado continua em posse do responsável pela descoberta e que o outro fragmento fluminense foi adquirido por estrangeiros no local por uma quantia irrisória. Após do bólido maior que explodiu como bola ser amostrado, o fragmento de Guaçuí-ES foi devolvido ao senhor Antônio Sobrinho pelos autores e adquirido um dia depois no local por pesquisadores do Museu Nacional-RJ. Não há registros desse tipo de queda de meteorito há quase duas décadas no Brasil. O último meteorito de queda registrada no país foi encontrado em Campos Sales, no Ceará, há 19 anos.

O objetivo do presente artigo é descrever e classificar o primeiro meteorito encontrado em terras do Estado do Espírito Santo, apresentado na Figura 2 , com base nos estudos petrográficos macro e microscópicos dos elementos texturais e mineralógicos, apoiados pela química mineral.

\section{Metodologia}

Para os estudos de petrografia macroscópica, a amostra do meteorito foi devidamente serrada com uma serra diamantada. Foi preparada uma lâmina delgada polida de uma seção representativa do material, a qual foi utilizada nos estudos micropetrográficos, suportados por um microscópio polarizador Leica DMR-XP de luz transmitida e refletida, com câmara fotográfica digital acoplada para a obtenção de fotomicrografias. Para efeito de comparação, as fotomicrografias do livro de Lauretta \& Killgore (2005) foram consultadas.

O material do meteorito da mesma lâmina foi investigado por meio da microssonda eletrônica JXA-Jeol-8900 RL WD/ED, instalada no Departamento de Física da Universidade Federal de Minas Gerais (UFMG), para determinações
Figura 3

Localização do ponto da queda dos meteoritos.

\section{Características gerais e petrografia macroscópica}

O meteorito é formado por material rochoso, em sua maioria constituído por minerais silicáticos, pesando aproximadamente 260 gramas e com peso específico 3,3 (mensurado em balança do tipo Jolly), em meio do qual se encontram dispersos pequenos nódulos com brilho metálico, que confere ao conjunto uma leve sus- ceptibilidade magnética (atração com um simples imã de mão).

Possui forma retangular, com quinas em ângulos retos e crosta de fusão preta, com espessura aproximada de $0,5 \mathrm{~mm}$. Da mesma forma que no meteorito de Varre-Sai, regmaglitos podem ser vistos na sua superfície, com diâmetros de apro- das composições químicas das fases minerais presentes. Os padrões utilizados para as microanálises dos minerais opacos foram Pirita (S), Fe-metal (Fe) e Ni-metal (Ni) e $\mathrm{Cr}_{2} \mathrm{O}_{3}(\mathrm{Cr})$ e para os demais minerais silicáticos foram Jadeíta $(\mathrm{Na})$, Microclina $(\mathrm{K})$, Rodonita $(\mathrm{Mn})$, $\mathrm{MgO}(\mathrm{Mg})$, Andradita (Ca), Magnetita (Fe), $\mathrm{Al}_{2} \mathrm{O}_{3}(\mathrm{Al})$, Rutilo (Ti), Ni-metal (Ni) e Quartzo (Si). ximadamente $1 \mathrm{~cm}$ e profundidade média de 2 a $4 \mathrm{~mm}$ (Figura 2).

A rocha possui coloração acinzentada, com nódulos metálicos milimétricos a submilimétricos, pequenos e raros glóbulos afaníticos com formas ovaladas e esféricas de coloração cinza esverdeada e dimensões de 1 a $5 \mathrm{~mm}$, além de con- 
creções félsicas afaníticas de 1 a 2 mm com formatos irregulares, todos dispersos em matriz afanítica cinza esverdeada (Figura 4).

Os nódulos metálicos normalmente apresentam bordas com alteração na forma de um material alaranjado. Fato que se destaca é que alguns nódulos iridescentes maiores aparecem preenchendo fraturas que vão de uma superfície a outra do espécime, com espessuras que variam de 0,2 a $0,5 \mathrm{~mm}$. Esta feição corresponde à típica deposição de opacos durante eventos de impacto ("shock") responsáveis pelo fraturamento do material.
Os glóbulos esverdeados, reconhecidamente côndrulos, apresentam-se pouco distintos da matriz (em raros casos, com borda bem delimitada - porção superior direita da Figura 4), o que permite inferir recristalização de praticamente todo o material rochoso.
Figura 4

Aspecto macroscópico do interior do meteorito de Guaçuí-ES. Notar côndrulo $(\mathrm{C})$ residual e deposição de nódulos (N) de opacos em fraturas.

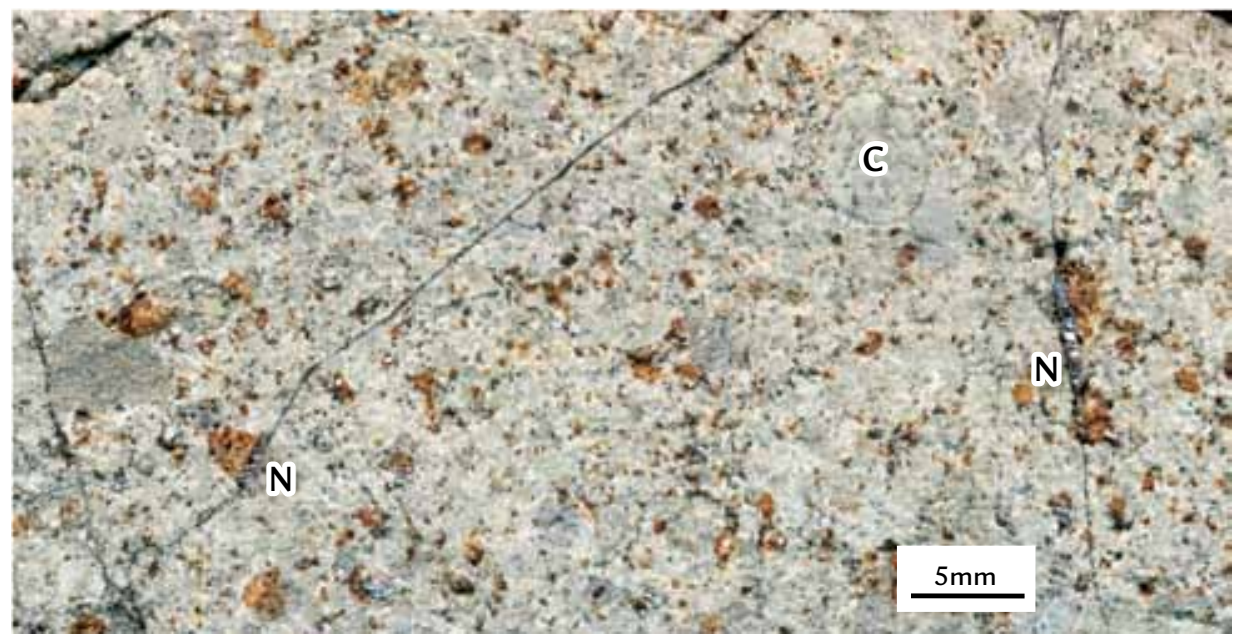

\section{Petrografia microscópica e química geral}

Sob luz transmitida ao microscópio polarizador, foi verificado que a mineralogia silicatada do meteorito de Guaçuí-ES é composta essencialmente por olivina (com extinção ondulante) e ortopiroxênio (extinção reta), com plagioclásio (às vezes com típica macla polissintética) e clinopiroxênio subordinados. As composições desses silicatos podem ser verificadas na Tabela 1 , cujos dados apontam para olivina (solução sólida rica em magnésio), enstatita com Fe (bronzita), oligoclásio e augita-(Cr).

Microscopicamente, a textura principal é inequigranular hipidiomórfica, salientando-se que a intensa recristalização do material rochoso inferida pelo aspecto difuso e obliterado dos côndrulos a olhonú pôde ser confirmada na investigação da lâmina delgada. Essa recristalização desfigura o aspecto ígneo original do meteorito em sua quase totalidade. Como se percebe na Figura 5, praticamente toda a matriz mostra-se recristalizada, com minerais apresentando junções tríplices com ângulos de $120^{\circ}$.

Com relação aos opacos, sob luz refletida, foram prontamente distinguidas
Figura 5

Fotomicrografias do aspecto geral (acima) e de detalhe (abaixo) do meteorito de Guaçuí-ES, com seus

minerais transparentes e opacos.

Nas fotos inferiores notam-se olivina, ortopiroxênio (alto relevo) e plagioclásio (límpidos, baixo relevo) que se tocam mutuamente através de junções tríplices típicas do fenômeno de recristalização.

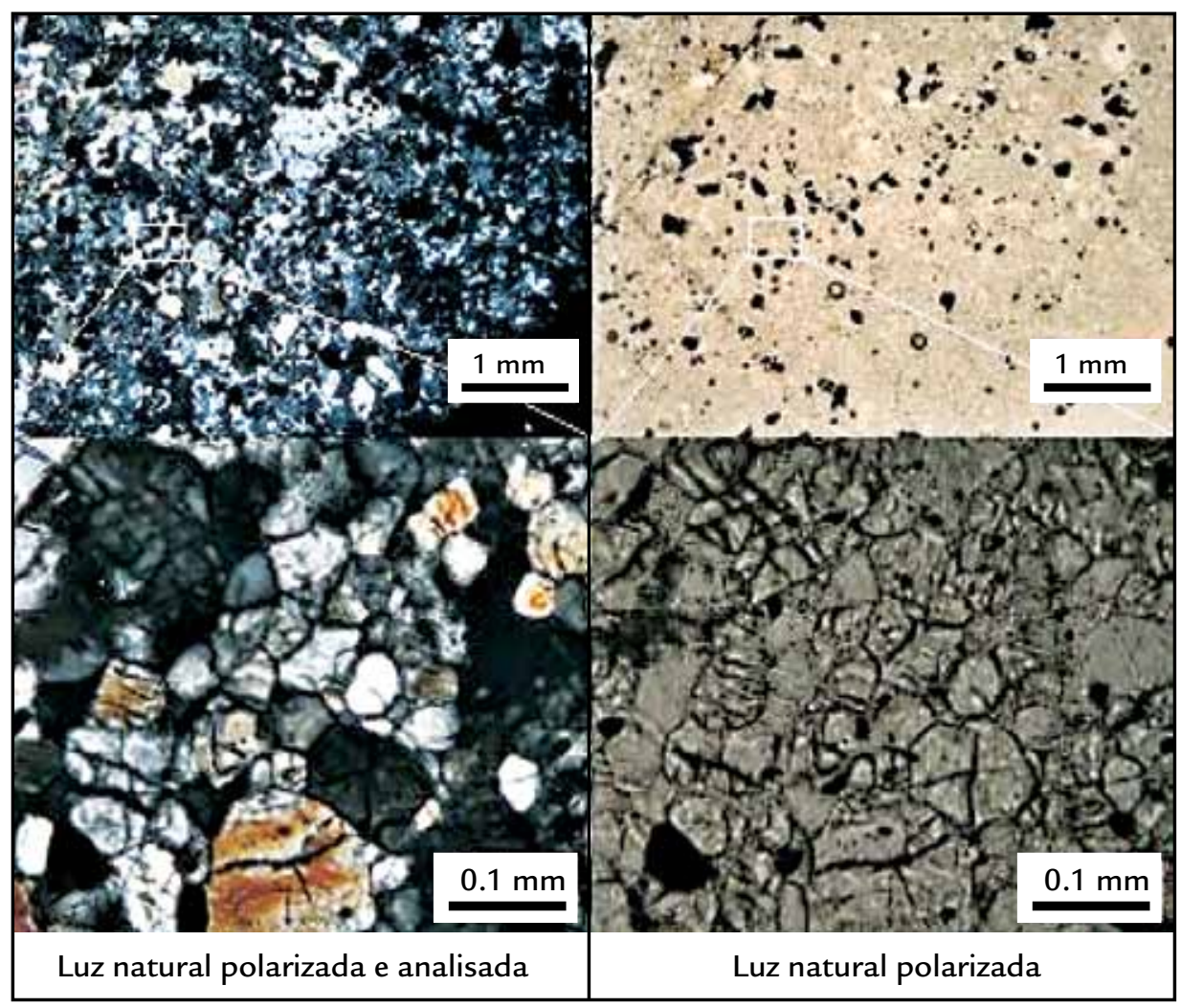




\begin{tabular}{|c|c|c|c|c|c|c|c|c|c|c|c|c|c|}
\hline No. & $\mathrm{Na}_{2} \mathrm{O}$ & $\mathrm{K}_{2} \mathrm{O}$ & $\mathrm{MnO}$ & $\mathrm{MgO}$ & $\mathrm{CaO}$ & $\mathrm{FeO}$ & $\mathrm{Al}_{2} \mathrm{O}_{3}$ & $\mathrm{TiO}_{2}$ & $\mathrm{NiO}$ & $\mathrm{SiO}_{2}$ & $\mathrm{Cr}_{2} \mathrm{O}_{3}$ & Total & Mineral \\
\hline 1 & 0.00 & 0.00 & 0.46 & 40.26 & 0.03 & 22.33 & 0.01 & 0.02 & 0.00 & 37.67 & 0.02 & 100.80 & \\
\hline 2 & 0.00 & 0.00 & 0.46 & 38.62 & 0.02 & 22.13 & 0.02 & 0.00 & 0.01 & 38.10 & 0.03 & 99.39 & Olivina \\
\hline 3 & 0.01 & 0.00 & 0.46 & 39.18 & 0.03 & 21.95 & 0.04 & 0.02 & 0.02 & 38.08 & 0.01 & 99.79 & S.S. \\
\hline Média & 0.00 & 0.00 & 0.46 & 39.35 & 0.03 & 22.14 & 0.02 & 0.01 & 0.01 & 37.95 & 0.02 & 99.99 & \\
\hline \multirow{3}{*}{$\begin{array}{c}\text { Cátions } \\
\text { base } 4 \\
\text { oxig. }\end{array}$} & & & Mn & Mg & & $\mathrm{Fe}$ & & & & $\mathrm{Si}$ & & & Fo76 \\
\hline & - & - & 0.01 & 1.528 & - & 0.482 & - & - & - & 0.989 & - & - & $\mathrm{Fa}_{24}$ \\
\hline & \multicolumn{13}{|c|}{$\left(\mathrm{Mg}_{0,75} \mathrm{Fe}_{0,24} \mathrm{Mn}_{0,01}\right)_{2} \mathrm{SiO}_{4}$} \\
\hline
\end{tabular}

\begin{tabular}{|c|c|c|c|c|c|c|c|c|c|c|c|c|c|}
\hline 4 & 0.03 & 0.00 & 0.47 & 29.71 & 0.57 & 13.41 & 0.16 & 0.20 & 0.01 & 55.00 & 0.11 & 99.67 & \\
\hline 5 & 0.01 & 0.01 & 0.46 & 29.57 & 0.63 & 13.41 & 0.18 & 0.22 & 0.01 & 54.84 & 0.11 & 99.44 & Enstatita \\
\hline 6 & 0.00 & 0.01 & 0.43 & 29.10 & 0.81 & 13.11 & 0.19 & 0.15 & 0.00 & 54.97 & 0.10 & 98.86 & com Fe \\
\hline 7 & 0.01 & 0.01 & 0.41 & 29.15 & 0.71 & 13.24 & 0.19 & 0.21 & 0.00 & 55.44 & 0.10 & 99.46 & (bronzita) \\
\hline 8 & 0.03 & 0.02 & 0.45 & 29.49 & 0.52 & 13.35 & 0.16 & 0.18 & 0.00 & 54.62 & 0.11 & 98.92 & \\
\hline Média & 0.02 & 0.01 & 0.44 & 29.40 & 0.65 & 13.30 & 0.18 & 0.19 & 0.00 & 54.97 & 0.11 & 99.27 & Wo 1 \\
\hline $\begin{array}{c}\text { Cátions } \\
\text { base } 6 \\
\text { oxig. }\end{array}$ & - & - & $\begin{array}{c}\mathrm{Mn} \\
0.01\end{array}$ & $\underset{1.574}{\mathrm{Mg}}$ & $\begin{array}{c}\mathrm{Ca} \\
0.025\end{array}$ & $\begin{array}{c}\mathrm{Fe} \\
0.399\end{array}$ & $\begin{array}{c}\mathrm{Al} \\
0.008\end{array}$ & $\begin{array}{c}\mathrm{Ti} \\
0.01\end{array}$ & - & $\begin{array}{l}\mathrm{Si} \\
1.973\end{array}$ & $\begin{array}{c}\mathrm{Cr} \\
0.003\end{array}$ & - & $\begin{array}{l}\text { En } 79 \\
\text { Fs } 20\end{array}$ \\
\hline
\end{tabular}

\begin{tabular}{|c|c|c|c|c|c|c|c|c|c|c|c|c|c|}
\hline 9 & 8.59 & 0.73 & 0.00 & 0.01 & 1.99 & 0.45 & 21.65 & 0.04 & 0.02 & 67.24 & 0.02 & & \\
\hline 10 & 8.47 & 0.89 & 0.00 & 0.05 & 2.14 & 0.28 & 21.06 & 0.04 & 0.01 & 66.00 & 0.00 & 98.94 & Oligoclásio \\
\hline 11 & 8.51 & 0.91 & 0.02 & 0.33 & 2.04 & 0.59 & 20.77 & 0.05 & 0.00 & 65.26 & 0.00 & 98.47 & \\
\hline 12 & 8.60 & 0.89 & 0.05 & 0.08 & 2.15 & 0.36 & 21.01 & 0.04 & 0.01 & 65.61 & 0.00 & 98.80 & Ab 84 \\
\hline Média & 8.54 & 0.86 & 0.02 & 0.12 & 2.08 & 0.42 & 21.12 & 0.04 & 0.01 & 66.03 & 0.01 & 99.24 & An 11 \\
\hline $\begin{array}{c}\text { Cátions } \\
\text { base } 32 \\
\text { oxig. }\end{array}$ & $\begin{array}{c}\mathrm{Na} \\
2.928\end{array}$ & $\begin{array}{c}\mathrm{K} \\
0.194\end{array}$ & - & $\underset{0.032}{\mathrm{Mg}_{2}}$ & $\begin{array}{c}\mathrm{Ca} \\
0.394\end{array}$ & $\begin{array}{c}\mathrm{Fe} \\
0.062\end{array}$ & $\underset{4.397}{\mathrm{Al}}$ & - & - & $\begin{array}{c}\mathrm{Si} \\
11.67\end{array}$ & - & & Or 5 \\
\hline
\end{tabular}

\begin{tabular}{|c|c|c|c|c|c|c|c|c|c|c|c|c|c|}
\hline 13 & 0.55 & 0.01 & 0.30 & 16.66 & 20.75 & 4.88 & 0.55 & 0.51 & 0.07 & 53.11 & 0.86 & 98.25 & \\
\hline 14 & 0.53 & 0.01 & 0.20 & 16.75 & 20.93 & 4.74 & 0.50 & 0.46 & 0.01 & 53.35 & 0.87 & 98.35 & Iugita- \\
\hline 15 & 0.48 & 0.02 & 0.26 & 16.42 & 20.82 & 4.55 & 0.51 & 0.47 & 0.00 & 53.00 & 0.86 & 97.38 & \\
\hline Média & 0.52 & 0.01 & 0.25 & 16.61 & 20.83 & 4.72 & 0.52 & 0.49 & 0.03 & 53.15 & 0.86 & 98.00 & \\
\hline $\begin{array}{l}\text { Cátions } \\
\text { base } 6\end{array}$ & $\begin{array}{c}\mathrm{Na} \\
\mathrm{M} 2 \\
0.038\end{array}$ & - & $\begin{array}{c}\text { Mn } \\
\text { M2 } \\
0.01\end{array}$ & $\begin{array}{c}\text { Mg } \\
\text { M1 }\end{array}$ & $\begin{array}{c}\mathrm{Ca} \\
\mathrm{M} 2 \\
0834\end{array}$ & $\begin{array}{c}\mathrm{Fe} \\
\mathrm{M} 1 \\
0.027\end{array}$ & $\begin{array}{c}\text { Al } \\
\text { M1 }\end{array}$ & $\begin{array}{c}\text { Ti } \\
\text { M1 } \\
0.01\end{array}$ & - & $\begin{array}{c}\mathrm{Si} \\
\mathrm{T} \\
\mathrm{T}\end{array}$ & $\begin{array}{c}\mathrm{Cr} \\
\mathrm{M} 1 \\
0.025\end{array}$ & & $\begin{array}{l}\text { Wo } 44 \\
\text { En } 48\end{array}$ \\
\hline oxig. & 0.038 & & 0.01 & & & $\begin{array}{c}0.027 \\
\text { M2 } \\
0.121\end{array}$ & $\begin{array}{c}0.009 \\
{ }^{\mathrm{T}} \\
0.014\end{array}$ & 0.01 & & & & & \\
\hline
\end{tabular}

$\left(\mathrm{Ca}_{0,83} \mathrm{Na}_{0,04} \mathrm{Fe}_{0,12} \mathrm{Mn}_{0,01}\right)\left(\mathrm{Mg}_{0,92} \mathrm{Fe}_{0,03} \mathrm{Cr}_{0,03} \mathrm{Al}_{0,01} \mathrm{Ti}_{0,01}\right)\left(\mathrm{Si}_{0,99} \mathrm{Al}_{0,01}\right)_{2} \mathrm{O}_{6}$

\begin{tabular}{|c|c|c|c|c|c|c|c|c|c|}
\hline No. & \multicolumn{2}{|c|}{$\mathbf{S}$} & \multicolumn{2}{|c|}{$\mathrm{Ni}$} & \multicolumn{2}{|c|}{$\mathrm{Fe}$} & \multicolumn{2}{|c|}{ Total } & Mineral \\
\hline 1 & \multicolumn{2}{|c|}{36.13} & \multicolumn{2}{|c|}{0.00} & \multicolumn{2}{|c|}{59.24} & \multicolumn{2}{|c|}{95.36} & \\
\hline 2 & \multicolumn{2}{|c|}{36.25} & \multicolumn{2}{|c|}{0.00} & \multicolumn{2}{|c|}{60.44} & \multicolumn{2}{|c|}{96.69} & Troilita \\
\hline 3 & \multicolumn{2}{|c|}{36.44} & \multicolumn{2}{|c|}{0.08} & \multicolumn{2}{|c|}{60.22} & \multicolumn{2}{|c|}{96.75} & Sulfeto \\
\hline Média & \multicolumn{2}{|c|}{36.27} & \multicolumn{2}{|c|}{0.03} & \multicolumn{2}{|c|}{59.97} & \multicolumn{2}{|c|}{96.27} & \\
\hline 4 & \multicolumn{2}{|c|}{0.03} & \multicolumn{2}{|c|}{3.62} & \multicolumn{2}{|c|}{92.81} & \multicolumn{2}{|c|}{96.45} & \multirow{4}{*}{$\begin{array}{c}\text { Kamacita (alfa Fe,Ni) } \\
\text { Liga metálica }\end{array}$} \\
\hline 5 & \multicolumn{2}{|c|}{0.01} & \multicolumn{2}{|c|}{4.20} & \multicolumn{2}{|c|}{90.84} & \multicolumn{2}{|c|}{95.05} & \\
\hline 6 & \multirow{2}{*}{\multicolumn{2}{|c|}{$\begin{array}{l}0.03 \\
0.02\end{array}$}} & \multicolumn{2}{|c|}{6.02} & \multicolumn{2}{|c|}{91.9} & \multicolumn{2}{|c|}{97.95} & \\
\hline Média & & & & 61 & & 85 & 96 & 48 & \\
\hline 7 & & $\overline{00}$ & & .25 & & 08 & 95 & 33 & \\
\hline 8 & & 00 & & 1.82 & & 87 & 97 & 69 & \\
\hline 9 & & 00 & & 5.54 & & 99 & 99 & 53 & ma re, $\left.\mathrm{NI}_{\mathrm{I}}\right) \quad\left[\mathrm{Fe}_{80} \mathrm{NI}_{20}\right]$ \\
\hline 10 & & 00 & & 1.98 & & 83 & 99 & 80 & \\
\hline Média & & 00 & & .90 & & 19 & 98 & 09 & \\
\hline 11 & & 15 & & .92 & & 21 & 97 & 27 & $\underset{\text { Letrataenita }(\mathrm{Fe}, \mathrm{Ni})}{\text { iga metálica }}\left[\mathrm{Fe}_{48} \mathrm{Ni}_{52}\right]$ \\
\hline No. & $\mathrm{MnO}$ & MgO & $\mathrm{FeO}$ & $\mathrm{Al}_{2} \mathrm{O}_{3}$ & $\mathrm{TiO}_{2}$ & $\mathrm{SiO}_{2}$ & $\mathrm{Cr}_{2} \mathrm{O}_{3}$ & Total & Mineral \\
\hline 12 & 0.63 & 2.29 & 30.04 & 6.05 & 2.76 & 0.05 & 55.32 & 97.13 & \\
\hline 13 & 0.67 & 2.86 & 29.32 & 5.95 & 2.83 & 0.19 & 55.06 & 96.87 & \\
\hline 14 & 0.72 & 3.39 & 28.07 & 5.53 & 3.06 & 0.38 & 55.43 & 96.57 & \\
\hline 15 & 0.67 & 2.07 & 29.24 & 5.81 & 2.57 & 0.57 & 54.78 & 95.70 & Cromita $\quad\left(\mathrm{Fe}_{0,84} \mathrm{Mg}_{0,14} \mathbf{M n}_{0,02}\right)$ \\
\hline Média & 0.67 & 2.65 & 29.17 & 5.84 & 2.81 & 0.30 & 55.15 & 96.57 & $\left(\mathrm{Cr}_{0,83} \mathrm{Al}_{0,13} \mathrm{Ti}_{0,03} \mathrm{Si}_{0,01}\right)_{2} \mathrm{O}_{4} \quad$ Oxido \\
\hline $\begin{array}{l}\text { Cátion } \\
\text { s base } \\
4 \text { oxig. }\end{array}$ & $\begin{array}{c}\mathrm{Mn} \\
0,021\end{array}$ & $\begin{array}{c}\mathrm{Mg} \\
0,144\end{array}$ & $\begin{array}{c}\mathrm{Fe} \\
0,891\end{array}$ & $\begin{array}{c}\text { Al } \\
0,251\end{array}$ & $\begin{array}{c}\mathrm{Ti} \\
0,077\end{array}$ & $\begin{array}{c}\mathrm{Si} \\
0,011\end{array}$ & $\begin{array}{c}\mathrm{Cr} \\
1,592\end{array}$ & - & \\
\hline
\end{tabular}

Tabela 1

Microanálises químicas das fases minerais silicáticas do meteorito de Guaçuí-ES obtidas por microssonda eletrônica.

Dados em \% em peso dos óxidos. Proporções catiônicas e fórmulas empíricas incluídas.
Tabela 2

Microanálises químicas das fases minerais opacas do meteorito de Guaçuí-ES obtidas por microssonda eletrônica. Dados em \% em peso dos elementos para as ligas e sulfeto e em \% em peso dos óxidos para o óxido. Proporções catiônicas e fórmulas empíricas incluídas. 
Figura 6

Fotomicrografia do meteorito de Guaçuí-ES vista sob luz refletida. Três tipos de minerais metálicos são identificados:

liga metálica (1), sulfeto (2) e óxido (3).

pelo menos três fases minerais principais distintas (Figura 6), cada uma com uma reflectância característica. Os sulfetos, com reflectância em tons de bronze, correspondem a $50 \%$ dos opacos. As ligas metálicas, as quais refletem tons de branco brilhante, perfazem $40 \%$ e os óxidos, em tons de cinza, representam cerca de $10 \%$ dos opacos. As composições destes opacos podem ser verificadas na Tabela 2 , cujos dados apontam para sulfeto de ferro (troilita-FeS), ligas Fe-Ni [kamacita (predominante)-taenita-tetrataenita] e óxido (cromita). A Figura 7 apresenta kamacita e taenita associadas, distinguidas com o auxílio de imagens de elétrons

Figura 7

Associação de ligas $\mathrm{Fe}, \mathrm{Ni}$ kamacita-taenita do meteorito de Guaçuí-ES em imagem de elétrons retro-espalhados.

A taenita mostra borda de exsolução rica em Ni causada por queda de temperatura.

Figura 8

Fotomicrografia sob luz natural polarizada e analisada de cristais arredondados de olivina precoce poiquiliticamente englobados por um cristal tardio de ortopiroxênio (enstatita com Fe).

Figura 9

Fotomicrografia de um côndrulo centro da foto - encontrado no interior do meteorito de Guaçuí (luz natural polarizada e analisada).

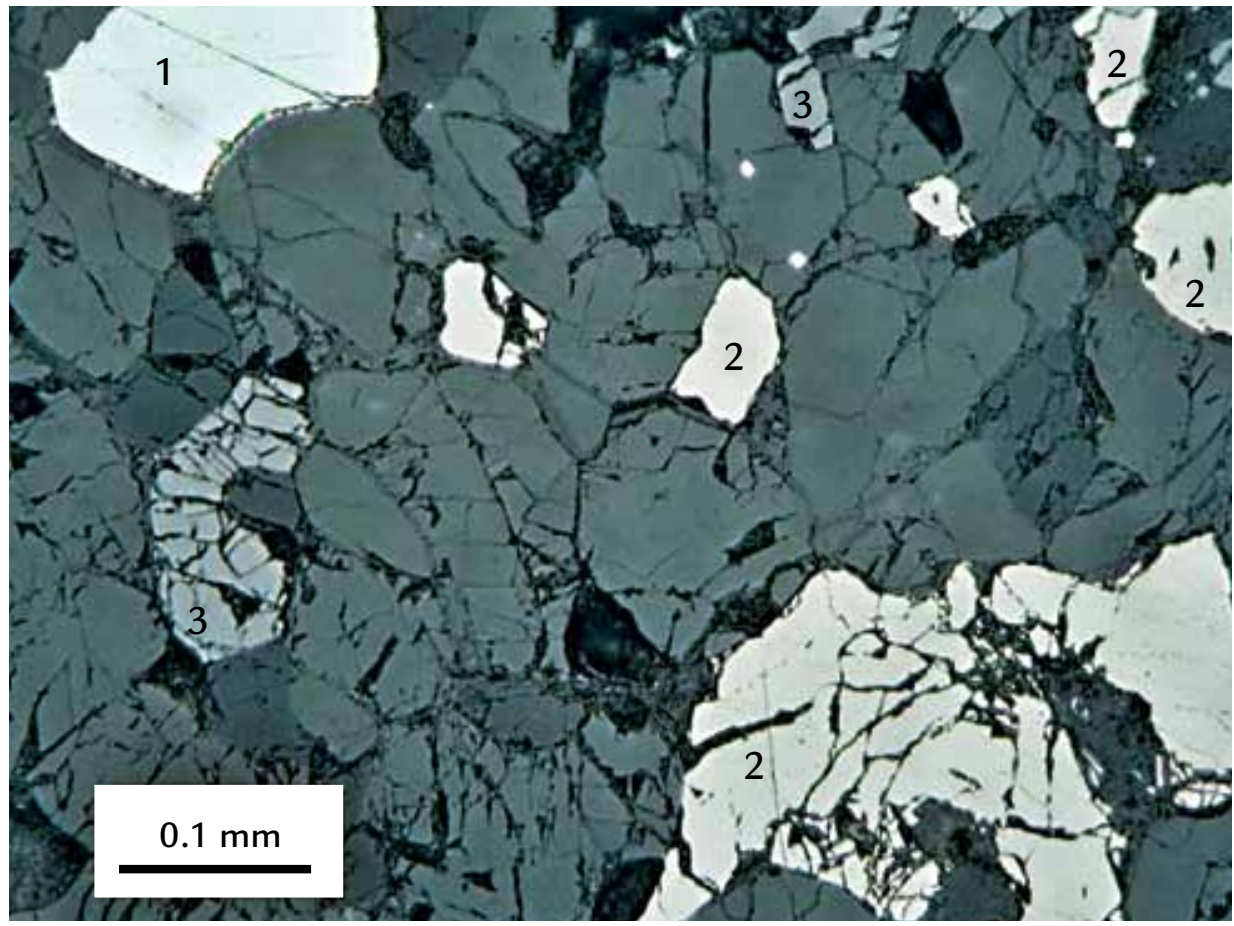

retro-espalhados.

Em termos petrográficos, cabe destacar as informações sobre a análise modal mineralógica, realizada em dez diferentes porções do meteorito montado na lâmina delgada. Essa análise modal foi obtida com o auxílio da microssonda eletrônica, através do software MAP ANALYSIS PROGRAM (JEOL, 2002), o qual realiza a análise percentual dos tons de cinza e branco das imagens de elétrons retroespalhados em uma determinada superfície. Ao analisar as diferentes tonalidades das diferentes fases minerais, a média dos resultados obtidos para as diferentes áreas investigadas apontou para $38 \%$ de olivina,
$31 \%$ de ortopiroxênio, $18 \%$ de plagioclásio, $2 \%$ de clinopiroxênio e $11 \%$ de opacos.

Em uma porção isenta de recristalização foi possível perceber a textura ígnea poiquilítica, na qual cristais arredondados de olivina são englobados por um cristal maior de ortopiroxênio (Figura 8). Essa feição aponta para o fato de que a olivina é de cristalização precoce em relação ao ortopiroxênio. Aparentemente, ambos os minerais cristalizaram-se anteriormente ao clinopiroxênio e plagioclásio, haja vista que estes últimos mostram-se, em sua maioria, dispersos nos interstícios dos cristais de olivina e ortopiroxênio.

Raros côndrulos preservados pude-
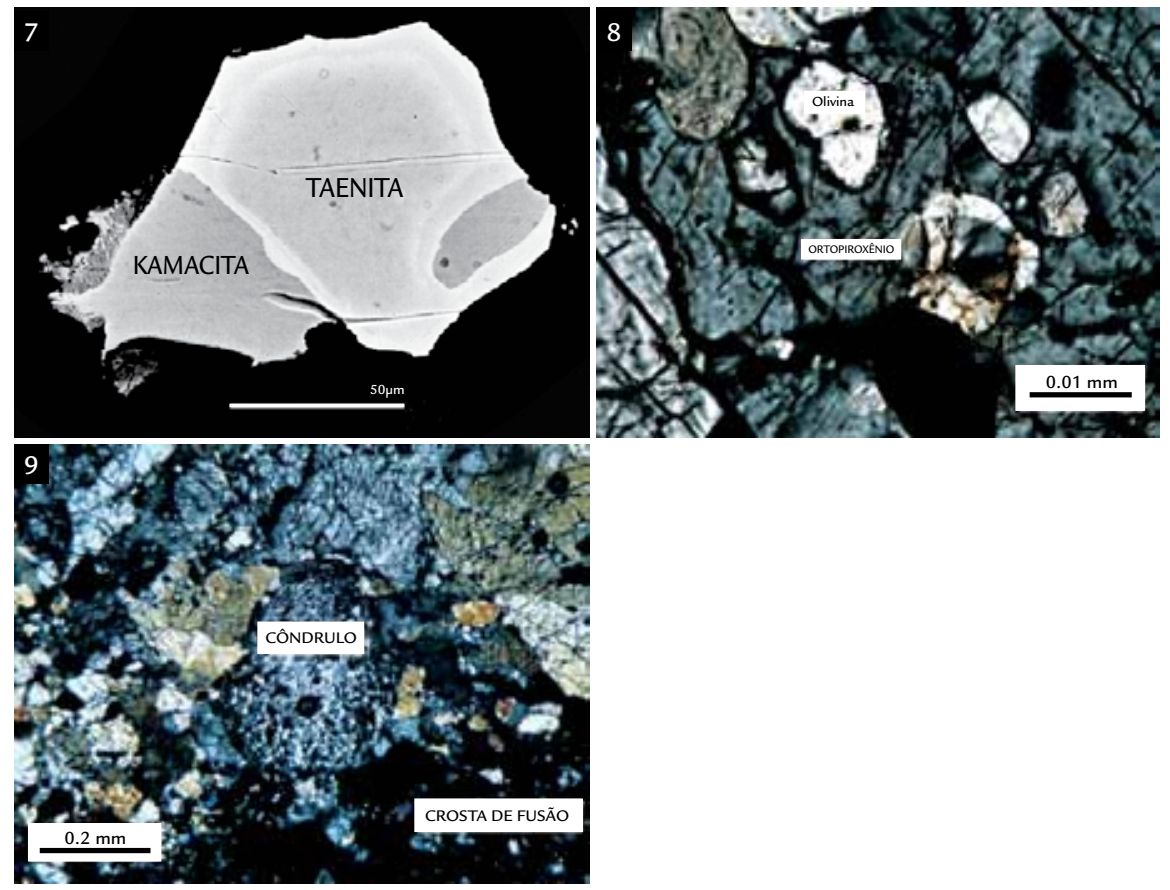
ram ser identificados em meio ao material recristalizado do meteorito (Figura 9). Eles são essencialmente constituídos por microcristais de enstatita com Fe (bronzita) e oligoclásio, com augita-(Cr) e opacos (troilita, liga Fe-Ni e cromita) subordinados. A maioria dos côndrulos mostra-se em aspecto difuso na massa recristalizada,
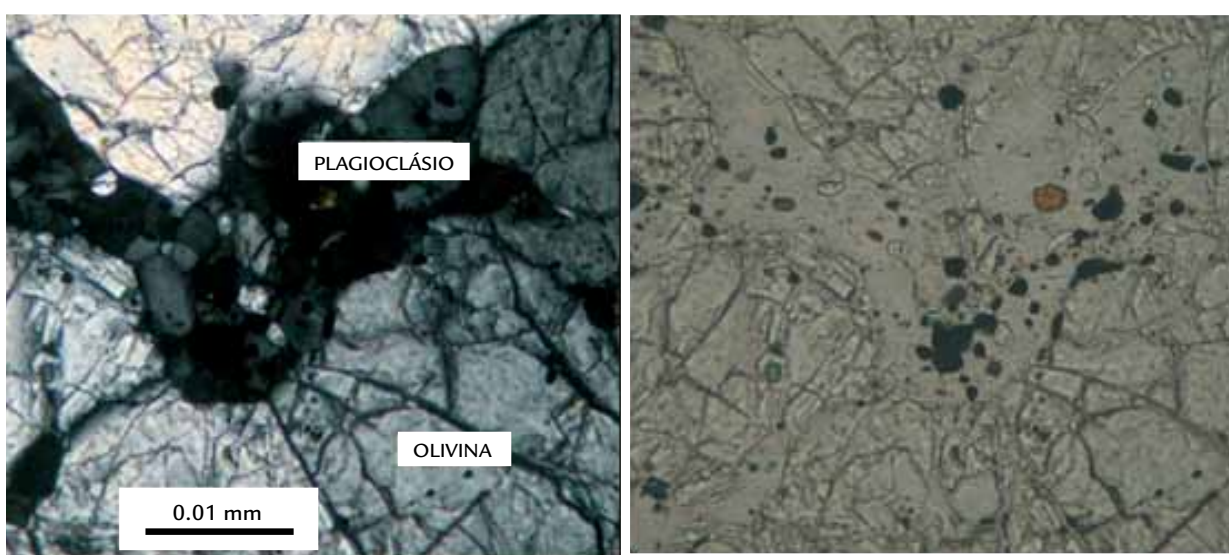

fundidos de outros silicatos de alto ponto de fusão como a olivina. Estas feições de fusão do plagioclásio, em associação à existência de fraturas com deposição de metal/troilita facilmente perceptíveis macroscopicamente (Figura 4), permitem inserir o meteorito de Guaçuí na classe S5 de Stöffler et al. (1991), ou seja, um meteorito que sofreu forte influência por impacto ("shock").

Os dados das microanálises dos minerais do meteorito de Guaçuí (Tabelas 1 e 2) associados à análise mineralógica modal mostram que ele apresenta quantidades significativas de $\mathrm{FeO}$ coexistindo com quantidades significativas de ferro com bordas já quase irreconhecíveis em escala microscópica.

O oligoclásio, constituinte de mais baixo ponto de fusão dentre os silicatos do meteorito, aparentemente passou por processos de fusão incipiente durante o evento de metamorfismo responsável pela recristalização dos minerais do meteorito.

metálico livre. Este fato posiciona o meteorito de Guaçuí no grupo dos condritos ordinários. Lançado no diagrama de Urey \& Craig (1953), o meteorito de Guaçuí fica posicionado próximo ao campo dos condritos ordinários de baixo Fe, ou seja, condritos ordinários tipo L (Figura 11).

No diagrama da variação do conteúdo de $\mathrm{FeO}$ em olivina e piroxênio coexistentes em condritos (Figura 12), o meteorito de Guaçuí situa-se novamente no campo dos condritos ordinários mais comuns, ou seja, aqueles do tipo L. Segundo Lewis (2004), a abundancia de metal livre decresce nos condritos ordinários do tipo $\mathrm{H}$ até o tipo LL e a razão dos cátions
Esse fato pode ser verificado na Figura 10, na qual o plagioclásio aparece como uma massa de cristais poligonalizados e parcialmente isotropizados (maskelynita), com contornos que lembram uma fusão, guardando vestígios de inclusões fundidas (melt inclusions) em tons de marrom escuro e fragmentos arredondados não
Figura 10

Fotomicrografias sob luz natural polarizada e analisada (esquerda) e luz natural polarizada (direita) com plagioclásio parcialmente vitrificado, guardando inclusões fundidas escuras (melt inclusions - aglomerado de pontos opacos arredondados na foto da direita).

divalentes $\left(\mathrm{Mg}^{2+}, \mathrm{Fe}^{2+}\right.$ e $\left.\mathrm{Ca}^{2+}\right)$ em relação ao silício aumenta substancialmente nesta série em função da oxidação do Fe. Portanto, a abundância da olivina nesta série aumenta na sequencia $\mathrm{H}$ para $\mathrm{L}$ e depois para LL. A importância do piroxênio vai diminuindo à medida que o teor de olivina aumenta. O condrito ordinário tipo $\mathrm{L}$ de Guaçuí apresenta alta razão dos cátions $\mathrm{Fe}, \mathrm{Mg}$ e $\mathrm{Ca}$ em relação à sílica e, por isso, apresenta predominânica de olivina sobre o piroxênio, do mesmo modo que seu teor em metal livre é relativamente reduzido por apresentar-se parcialmente oxidado comparativamente a um condrito ordinário tipo $\mathrm{H}$.

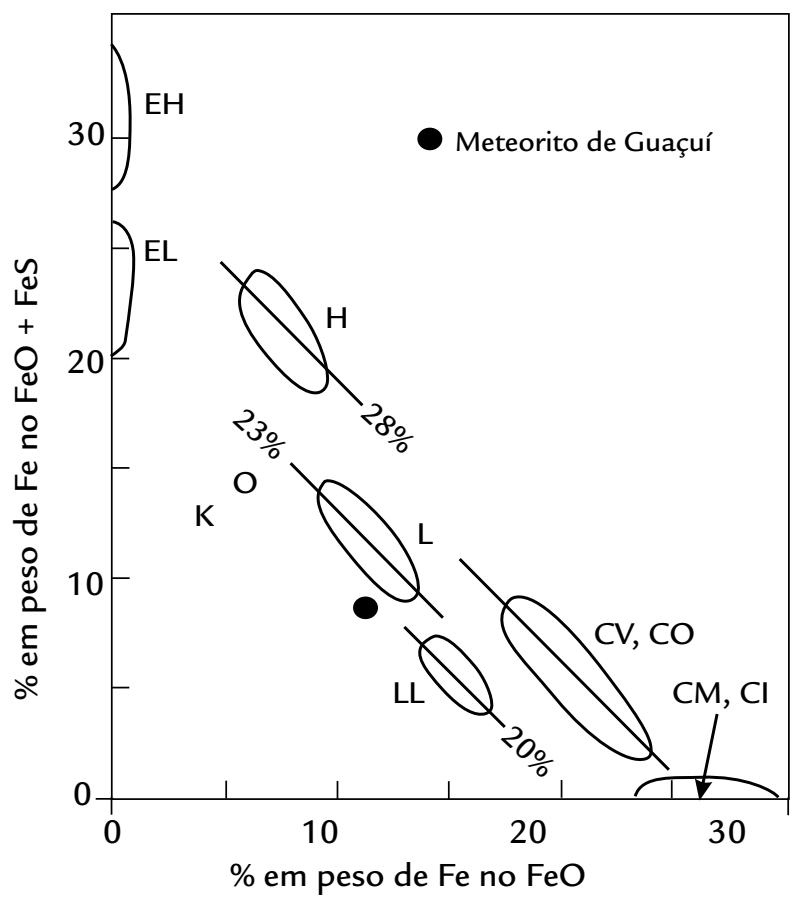

E - Enstatita condritos $(\mathrm{EH}=$ alto $\mathrm{Fe}, \mathrm{EL}=$ baixo $\mathrm{Fe})$

H, L, LL, K - Condritos ordinários com alto, baixo, muito baixo e extremamente baixo $\mathrm{Fe}$, respectivamente

C - Condritos carbonáceos $(\mathrm{CV}, \mathrm{CO}, \mathrm{CM}, \mathrm{Cl})$
Figura 11

Diagrama Urey-Craig de classificação de condritos. O condrito ordinário de Guaçuí pode ser classificado como do tipo L (baixo Fe). 


\section{Discussões e conclusões}

O entendimento sobre a classificação correta dos meteoritos condríticos e acondríticos encontra-se atualmente em construção. Acondritos são meteoritos rochosos formados pela fusão do corpo

Figura 12

Diagrama da variação do conteúdo de $\mathrm{FeO}$ em olivina e piroxênio coexistentes em condritos (Lewis, 2004). O meteorito de Guaçuí situa-se no campo dos condritos ordinários mais comuns, ou seja, aqueles do tipo L.

característica dos condritos.

Na prática, os condritos são amostras primitivas e substancialmente não fundidas de sólidos da antiga nébula do sistema solar que não sofreram separações de fases dirigidas pela diferença de densidade (diferenciação geoquímica). Nos condritos, os côndrulos tendem a se destacar texturalmente no material do meteorito. Porém, como em toda regra parental. Eles testemunham processos de diferenciação interna do corpo parental e perderam boa parte do seu conteúdo metálico original. Há diferentes categorias de acondritos (condritos fundidos, rochas ígneas basálticas e brechas regolíticas planetárias), os quais diferem dos condritos primeiramente pela ausência de côndrulos - gotas esféricas de material parcialmente fundido - que representam a principal

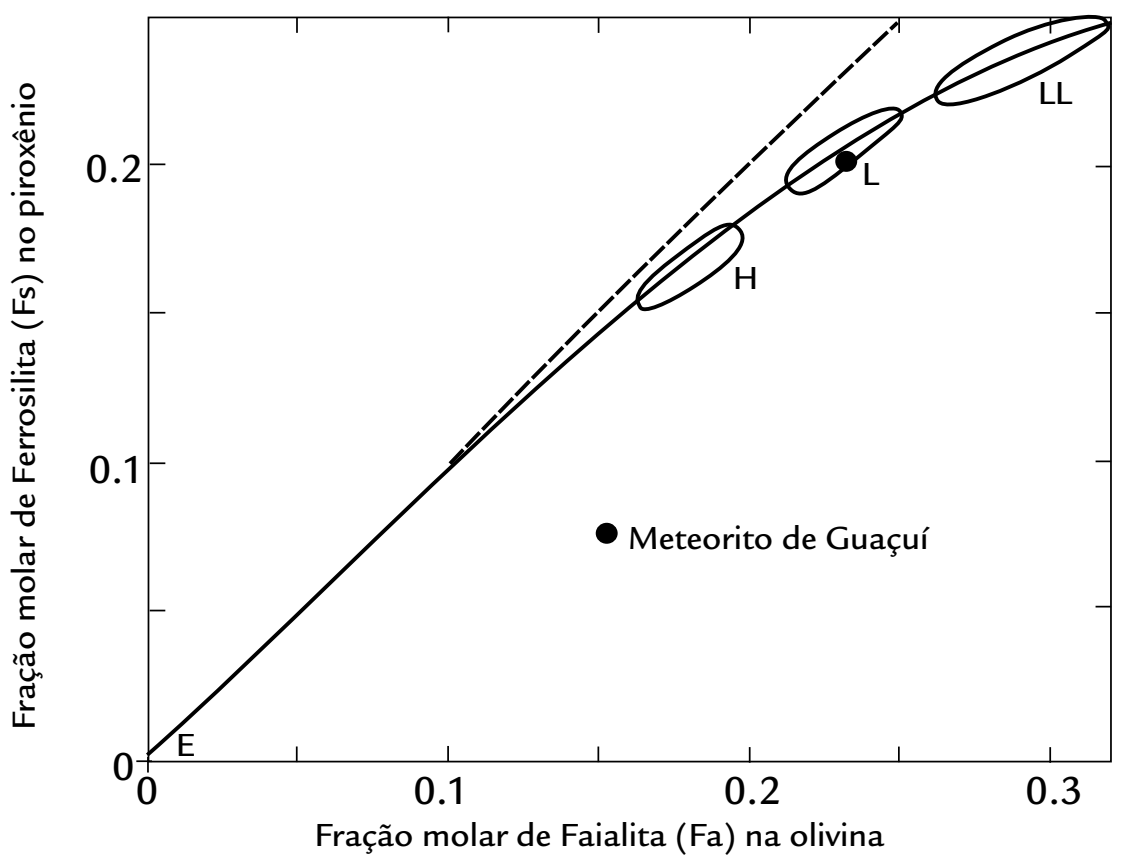

há exceção, são conhecidos raros condritos com quase ausência de côndrulos (p.ex. NWA1321-EL6), e contrariamente, existem raros acondritos primitivos que possuem alguns condritos em sua estrutura (p.ex. acapulcoitos). Essas exceções marcam a transição entre as duas classes. Tal transição, mostrada em pontilhado na Figura 13, ainda não é totalmente compreendida (Grady, 2000).
Pelo fato do meteorito de Guaçuí não ter atingido o grau petrológico $6 \mathrm{de}$ metamorfismo (Van Schmus \& Wood, 1967), o qual seria marcado pelo aparecimento de grandes cristais secundários de feldspato e a quase completa desfiguração dos côndrulos, ele não estaria inserido nos limites da transição entre condritos e acondritos, o que adicionalmente descartaria a tentativa de classificá-lo como acondrito.
Figura 13

Classificação dos meteoritos segundo o Catálogo de Meteoritos do Museu de História Natural de Londres (Grady, 2000).

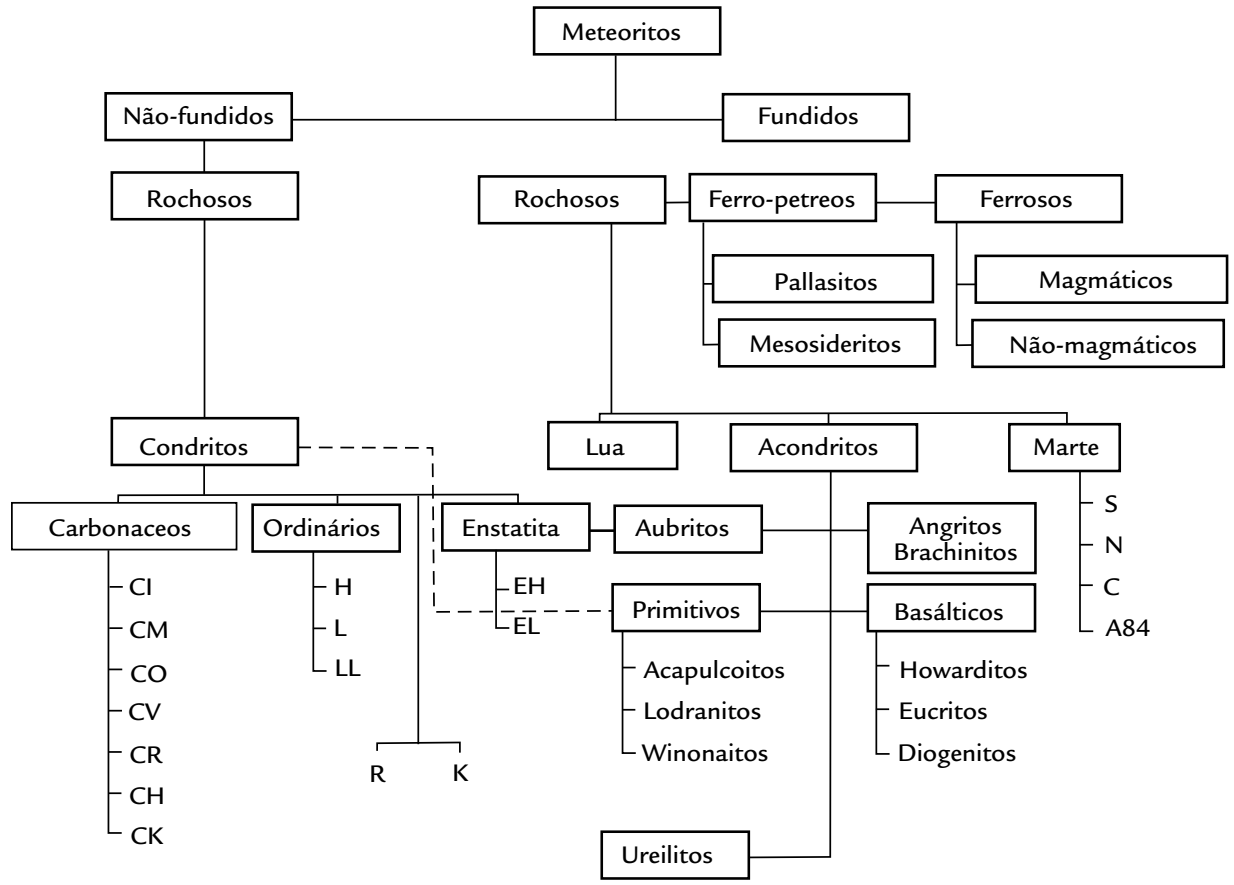


Tendo em vista as feições químicas, mineralógicas e texturais apresentadas para o condrito ordinário de Guaçuí, ele pode ser classificado no grau petrológico 5 de Van Schmus \& Wood (1967). Essa

\section{Agradecimentos}

À Prefeitura Municipal de Guaçuí e ao Sr. Antônio Jevu Sobrinho, pelo forne-

cimento do material condrítico para esse estudo classificatório.

\section{Referências bibliográficas}

GRADY M.M. Catalogue of meteorites. 5th edition. Cambridge University Press. United Kingdom. 2000, 696 p.

JEOL - XM-17330/27330 Map analysis program. Instruction Manual. Japan. 2002. 72p.

LAURETTA D.S., KILLGORE M. A color atlas of meteorites in thin section. Golden Retriever Publications. South Korea, 2005. 301 p.

LEWIS J.S. Physics and chemistry of the Solar System. (2. ed.). Elsevier Academic Press. USA. 2004, 643p.

STÖFFLER D., KEIL K., SCOTT E.R.D. Shock metamorphism of ordinary chondrites. Geochimica et Cosmochimica Acta, v. 55, p. 3845-3867, 1991.

UREY H.C., CRAIG H. The composition of the stone meteorites and the origin of the meteorites. Geochimica et Cosmochimica Acta 4: 36-xx. 1953.

VAN SCHMUS W.R., WOOD J.A. A chemical-petrologic classification for the chondritic meteorites. Geochimica et Cosmochimica Acta, v. 31, p. 747-765, 1967.

Artigo recebido em 29 de setembro de 2010. Aprovado em 17 de novembro de 2010. 